\title{
The Impact of COVID-19 on Electrophysiology Procedure Volume
}

\author{
Naga Venkata Pothineni ${ }^{1}$, Pasquale Santangeli ${ }^{2}$, Rajat Deo ${ }^{1}$, Francis Marchlinski ${ }^{1}$, and \\ Matthew Hyman ${ }^{1}$ \\ ${ }^{1}$ University of Pennsylvania Perelman School of Medicine \\ ${ }^{2}$ University of Pennsylvania
}

June 15,2020

\begin{abstract}
The COVID-19 pandemic has had a profound effect on the practice of clinical medicine. Tremendous resources have been poured into caring for patients infected with the virus necessitating a reduction in elective medical procedures. The extent to which physicians have modified their behavior in treating non-COVID-19 patients remains unclear. To address this question, we queried major cardiology vendors (Boston Scientific, Abbott and Biosense Webster) in the Philadelphia region to quantify arrhythmia ablation and cardiac device implantation volumes at 27 hospitals. We observed a significant, inverse correlation between regional COVID-19 cases and cardiac electrophysiologic procedures since the beginning of the US outbreak in late January. Furthermore, we observed that atrial fibrillation ablation and ICD implantation rates dropped more than VT ablation and device generator change rates did consistent with a shift away from elective medical procedures. These results can inform expected procedural volume load and planning once routine clinical practice resumes.
\end{abstract}

\section{Hosted file}

EP volume paper JCE.docx available at https://authorea.com/users/333781/articles/459878-theimpact-of-covid-19-on-electrophysiology-procedure-volume 